\title{
ANALISIS KEPUASAN PENGUNJUNG PERPUSTAKAAN UNIVERSITAS PROF. DR. HAZAIRIN, SH BENGKULU
}

\author{
Markoni \\ Fakultas Ekonomi Universitas Prof. Dr. Hazairin SH Bengkulu \\ Email: markoniaswan@gmail.com
}

\begin{abstract}
Abstrak
Melalui Penelitian ini diharapkan mendapatkan gambaran tentang bagaimana Kepuasan Pengunjung Perpustakaaan Universitas Prof. Dr. Hazairin, SH Bengkulu. Penelitian ini menggunakan sampel sebanyak 50 Orang dengan teknik accidental sampling. Pengumpulan Data menggunakan Kuisioner, dan analisa data menggunakan metode Customer Satisfaction Index (CSI), dengan memperhitungkan tingkat Kepentingan Pengunjung dan Tingkat Kinerja Pegawai. Aspek-aspek yang dinilai meliputi Ketersediaan Referensi, Kejelasan Informasi, Kecepatan Pelayanan, Jaringan Internet, Keramahan Petugas serta Kenyamanan Ruang Baca.

Dari hasil analisis data diperoleh Nilai Customer Satisfaction Indeks (CSI) atau indeks kepuasan Pengunjung Perpustakaan Unihaz adalah sebesar 66,15 \%. Hal ini menunjukkan bahwa Pengunjung Perpustakaan Unihaz Bengkulu dapat dikatakan puas. Ditinjau dari tingkat Kepentingan, dari semua aspek yang diteliti, asfek asfek yang menurut pengunjung sangat Penting dan perlu terus ditingkatkan terutama asfek Ketersediaan Referensi, Jaringan Internet, serta kenyamanan ruang baca. Sedangkan asfek asfek yang perlu mendapat perhatian agar kepentingan pengunjung Perpustakaan dapat terpenuhi dan mendapat kepuasan adalah Kecepatan Pelayanan, Kejelasan Informasi, serta Keramahan Pegawai

Sebaliknya dari ke-enam asfek Penilaian terhadap tingkat Kinerja pegawai, maka asfek asfek yang perlu diperbaiki dan ditingkatkan terutama asfek Kejelasan Informasi Kecepatan Pelayanan serta Keramahan Pegawai Perpustakaan Unihaz.
\end{abstract}

Kata Kunci : Kepuasan Pengunjung

Abstract

Through this research, it is expected to get an overview of how the Visitor Satisfaction of the University Library Prof. Dr. Hazairin, SH Bengkulu. This study used a sample of 50 people with accidental sampling technique. Data collection uses questionnaires, and data analysis using the Customer Satisfaction Index (CSI) method, taking into account the Visitor's Interest and Employee Performance Levels. The aspects assessed include Availability of Reference, Clarity of Information, Speed of Service, Internet Network, Hospitality of Officers and Comfort of Reading Room.

From the results of data analysis obtained the Value of Customer Satisfaction Index (CSI) or the index of satisfaction of Unihaz Library Visitors is $66.15 \%$. This shows 
that visitors to the Unihaz Bengkulu Library can be said to be satisfied. Judging from the level of importance, from all aspects studied, asfek asfek which according to visitors is very important and needs to be improved, especially asfek Availability Reference, Internet Network, and the convenience of the reading room. While asfek asfek that needs attention so that the interests of visitors of the Library can be fulfilled and get satisfaction is the Speed of Service, Clarity of Information, and Friendliness of Staff

On the contrary, from the sixth aspect of the assessment of the level of employee performance, the asfek asfek that needs to be improved and improved especially asfek Clarity Information Speed of Service and Hospitality of Unihaz Library Staff.

\section{Keywords: Visitor Satisfaction}

\section{LATAR BELAKANG}

Pendidikan dapat dikatakan merupakan bagian dari Investasi di bidang Sumber Daya Manusia. Sebagai Investasi, maka pendidikan harus dikelola dengan baik agar pendidikan tersebut dapat mencapai tujuan yang diinginkan yaitu sumber daya manusia yang berkualitas. bila sistem pendidikan suatu negara baik, maka akan menghasilkan Sumber Daya Manusi yang baik pula. Sumber daya Manusia yang baik merupakan Modal Dasar yang akan berdampak pada keberhasilan pembangunan suatu Bangsa secara keseluruhan, karena sumberdaya manusia itu merupakan subyek dan sekaligus sebagai obyek pembangunan suatu negara.

Ukuran tingkat Kinerja Pembangunan Manusia suatu Negara yang populer dan digunakan oleh Organisasi United Nations Development Programme (UNDP) adalah Indeks Pembangunan Manusia (IPM) atau Human Develompm,ent Index (HDI). Salah satu Indikator dari Indeks Pembangunan Manusia (IPM) tersebut adalah Indeks Pendidikan yaitu Angka Melek Huruf dan Lama Sekolah.

Peringkat Indeks Pembangunan Manusia (IPM) Indonesia pada Tahun 2018 berada di peringkat ke 116 dari 189 negara bersama dengan Negara Vetnam. Peringkat tersebut berada di urutan ke enam (6) jika dibandingkan dengan negara negara ASEAN lainnya, yaitu di bawah negara Singapura (Peringkat ke 9), Negara Brunai Darussalam (Peringkat ke 39), Negara Malaysia (peringkat ke 57), Negara Thailand (Peringkat ke 83) dan Negara Filiphina (peringkat ke 113).

Berdasarkan Peringkat HDI tersebut, Pembangunan Manusia Indonesia masih jauh dibandingkan dengan negara negara di dunia, demikian juga jika dibandingkan dengan sesama negara negara Asia Tenggara. Oleh karena itu maka sektor pendidikan haruslah mendapat perhatian dan dikelola dengan sungguh sungguh, tidak hanya oleh pemerintah saja tetapi juga oleh masyarakat.

Universitas Prof. Dr. Hazairin, SH Bengkulu adalah perguruan tinggi swasta di Provinsi Bengkulu yang diselenggarakan oleh Yayasan Semarak Bengkulu, mempunyai visi Menjadi Universitas yang Semarak, Religius dan Unggul dalam Penyelenggaraan Tridharma Perguruan Tinggi. Untuk mencapai Visi tersebut Universitas Prof. Dr. Hazairin, 
SH Bengkulu terus, Unihaz terus berbenah, baik dalam sarana dan prasarana pendidikan maupun dalam hal upaya pelayanan prima kepada mahasiswa.

Perpustakaan Universitas Prof. Dr. Hazairin, SH Bengkulu sebagai salah satu Unit Pelaksana Teknis mempunyai tugas dan fungsi memberikan pelayanan kepada mahasiswa, dosen dan pengunjung lainnya, baik dalam penyediaan referensi, Kenyamanan, Kenyamanan Ruang Baca, maupun bentuk pelayanan lainnya. Kepuasan Pengunjung Perpustakaan menunjukkan tingkat kinerja pegawai Perpustakaan.

Untuk memberikan pelayanan yang prima sehingga setiap pengunjung Perpustakaan merasa puas, Lembaga Penjaminan Mutu Universitas Prof. Dr. Hazairin, SH Bengkulu telah menetapkan Standar Mutu pada UPT Perpustakaan, yang meliputi Pedoman Pelaksanaan, Standar Operasional Prosedur (SOP) dan sebagainya. Proses penjaminan mutu itu sendiri selalu di pantau dan dievaluasi agar pelaksanaan pelayanan sesuai dengan standar mutu yang sudah ditetapkan.

\section{RUMUSAN MASALAH}

Permasalahan yang akan dibahas adalah bagaimana kepuasan Pengunjung Perpustakaan Universitas Prof. Dr, Hazairin, SH Bengkulu

\section{TUJUAN PENELITIAN}

Tujuan dari penelitian ini adalah untuk mengetahui tingkat kepuasan Pengunjung Perpustakaan Universitas Prof. Dr, Hazairin, SH Bengkulu

\section{TINJAUAN PUSTAKA}

\section{Perpustakaan}

Dalam Undang-Undang Nomor 43 Tahun 2007 "perpustakaan adalah institusi pengelola koleksi karya tulis, karya cetak, dan/ atau karya rekam secara profesional dengan sistem yang baku guna memenuhi kebutuhan pendidikan, penelitian, pelestarian, informasi, dan rekreasi bagi para pemustaka" http://amarsuteja.blogspot.com/2013/01/kepuasan-pengunjung-perpustakaan.html

Menurut Muchlisin Riadi, Perpustakaan adalah suatu unit kerja dari sebuah lembaga pendidikan yang berupa tempat penyimpanan buku-buku pustaka untuk menunjang proses pendidikan. (https://www.kajianpustaka.com/2012/11/ perpustakaan.html)

2. Pelayanan

Menurut Kotler (2003:464) pelayanan (Service) ialah sebagai suatu tindakan ataupun kinerja yang bisa diberikan pada orang lain. https://www.seputarpengetahuan.co.id/ 2016/10/ pengertian-pelayanan-menurut-para-ahli-lengkap.html 
Menurut Freed luthans (1995:46 pelayanan adalah sebuah proses pemenuhan kebutuhan melalui aktifitas orang lain yang menyangkut segala masalah yang ditujukan orang lain untuk menyeleaikan masalah. https://www.seputarpengetahuan.co.id/2016/10/pengertian-pelayanan-menurut-paraahli-lengkap.html

\section{Kepuasan}

Kepuasan menurut keputusan MENPAN No. KEP/25/M.PAN/2/2004 adalah hasil pendapat dan penilaian masyarakat terhadap kinerja pelayanan yang diberikan oleh aparatur penyelenggara pelayanan publik. http://amarsuteja.blogspot.com/2013/ 01/kepuasan-pengunjung-perpustakaan.html

Menurut Gibson (1987) kepuasan seseorang berarti terpenuhnya kebutuhan yang diinginkan yang diperoleh dari pengalaman melakukan sesuatu, pekerjaan, atau memperoleh perlakuan tertentu dan memperoleh sesuatu sesuai kebutuhan yang diinginkan. $\quad$ http://amarsuteja.blogspot.com/2013/01/kepuasan-pengunjungperpustakaan.html

\section{KERANGKA ANALISIS} sebagai berikut:

Secara skematis Kerangka Analisis dalam penelitian ini dapat digambarkan

\begin{tabular}{|c|c|c|}
\hline Indikator Pelayanan & \multirow{5}{*}{$\begin{array}{l}\text { Kualitas } \\
\text { Pelayanan }\end{array}$} & \multirow{5}{*}{$\begin{array}{c}\text { Tingkat } \\
\text { Kepuasan } \\
\text { Pengunjung }\end{array}$} \\
\hline Ketersediaan Referensi & & \\
\hline Kejelasan Informasi & & \\
\hline Kecepatan Pelayanan & & \\
\hline Jaringan Internet & & \\
\hline Keramahan Pegawai & & \\
\hline Kenyamanan Ruang Baca & & \\
\hline
\end{tabular}

Indeks

Kepuasan

Pengunjung

(Customer

Satisfaction index)

Untuk mengetahui kepuasan pengunjung Perpustakaan Unihaz, Analisis dilakukan terhadap Pelayanan Perpustakaan yang meliputi Ketersediaan Referensi, Kejelasan Informasi, Kecepatan Pelayanan, Jaringan Internet, Keramahan Pegawai, dan Kenyamanan Ruang Baca. Kualitas Pelayanan terhadap pengunjung Perpustakaan Unihaz akan mempengaruhi Tingkat Kepuasan Pengunjung, dan Tingkat Kepuasan Pengunjung tersebut 
di ukur dengan menggunakan alat analisis Indeks Kepuasan Pengunjung (Customer Satisfaction index)

\section{METODE PENELITTIAN}

Penelitian ini bersifat deskriptif dengan menggunakan data Primer dan data Sekunder. Populasi penelitian meliputi semua Pengunjung Perpustakaan dengan lima puluh (50) orang sampel. Pengambilan sampel dilakukan dengan teknik accidental sampling, dan Pengumpulan data dilakukan dengan penyebaran Kuisioner.

\section{METODE ANALISIS}

Penelitian ini menggunakan alat analisis Indeks Kepuasan Pengunjung yaitu Customer Satisfaction Index (CSI), dengan memperhitungkan Kepentingan Pengunjung dan Kinerja Pegawai, yang dilihat dari aspek aspek sebagai berikut :
1. Ketersediaan Referensi
2. Kejelasan Informasi
3. Kecepatan Pelayanan
4. Jaringan Internet
5. Keramahan Pegawai
6. Kenyamanan Ruang Baca

Masing masing aspek yang dinilai tersebut diberi skor dengan skala 1 sampai dengan 5 sesuai dengan jawaban Responden, seperti tersebut pada Tabel 2 berikut ini:

Tabel I

Pedoman Penilaian

\begin{tabular}{|l|c|c|l|c|c|}
\hline \multicolumn{3}{|c|}{ Tingkat Kepentingan } & \multicolumn{3}{c|}{ Tingkat Kinerja } \\
\hline Jawaban Responden & Singkatan & Score & Jawaban Responden & Singkatan & Score \\
\hline Sangat tidak penting & STP & 1 & Sangat tidak baik & STB & 1 \\
\hline Tidak penting & TP & 2 & Tidak baik & TB & 2 \\
\hline Cukup penting & CP & 3 & Cukup baik & CB & 3 \\
\hline Penting & P & 4 & Baik & B & 4 \\
\hline Sangat penting & SP & 5 & Sangat baik & SB & 5 \\
\hline
\end{tabular}

Nilai masing masing aspek yang dinilai tersebut selanjutnya dilakukan rekapitulasi dan dirata-ratakan, dan dilanjutkan dengan menghitung Indeks Kepuasan Pengunjung (IKP) dengan Metode Customer Satisfaction Index (CSI) sbb:

Customer Satisfaction Index $(\mathrm{CSI})=($ Weighted total : 5$)$ X $100 \%$. 


\section{ANALISIS}

Berdasarkan hasil pengolahan data dari jawaban responden diperoleh nilai-nilai tingkat kepentingan dan kinerja sebagai berikut :

\section{Tabel II}

Nilai tingkat kepentingan dan tingkat kinerja dilihat dari Ketersediaan Referensi

\begin{tabular}{|c|c|c|c|c|c|c|c|c|c|c|c|c|}
\hline \multirow{4}{*}{ Uraian } & \multicolumn{6}{|c|}{ Tingkat kepentingan } & \multicolumn{6}{|c|}{ Tingkat kinerja } \\
\hline & \multicolumn{5}{|c|}{ Tingkat penilaian } & \multirow{3}{*}{ Total } & \multicolumn{5}{|c|}{ Tingkat penilaian } & \multirow{3}{*}{ Total } \\
\hline & STP & $\mathrm{TP}$ & $\mathrm{CP}$ & $\mathrm{P}$ & $\mathrm{SP}$ & & STB & $\mathrm{TB}$ & $\mathrm{CB}$ & B & $\begin{array}{l}\mathrm{S} \\
\mathrm{B}\end{array}$ & \\
\hline & 1 & 2 & 3 & 4 & 5 & & 1 & 2 & 3 & 4 & 5 & \\
\hline Jumlah responden & 0 & 0 & 3 & 10 & 37 & 50 & 0 & 0 & 16 & 22 & 12 & 50 \\
\hline Persentase $(\%)$ & 0 & 0 & 6 & 20 & 74 & 100 & 0 & 0 & 32 & 44 & 24 & 100 \\
\hline $\begin{array}{l}\text { Jumlah bobot } \\
\text { penilaian }\end{array}$ & 0 & 0 & 9 & 40 & 185 & 234 & 0 & 0 & 48 & 88 & 60 & 196 \\
\hline \multicolumn{6}{|c|}{ Skor rata - rata } & 4.68 & \multicolumn{5}{|c|}{ Skor rata - rata } & 3.92 \\
\hline
\end{tabular}

Sumber : Hasil Penelitian 2019

Dari aspek Ketersediaan Referensi tersebut, Pengunjung Perpustakaan menganggap Ketersediaan Referensi Sangat Penting sebanyak $74 \%$ responden, dengan jumlah bobot penilaian 185, dengan rata-rata tingkat penilaian 4,68. Sedangkan dilihat dari tingkat kinerja pegawai sebagian besar pengunjung perpustakaan Unihaz menganggap baik (44\%) dengan bobot penilaian 88, dengan rata-rata tingkat penilaian 3,92 .

Tabel III

Nilai kepentingan dan kinerja dilihat dari Kejelasan Informasi

\begin{tabular}{|c|c|c|c|c|c|c|c|c|c|c|c|c|}
\hline \multirow{4}{*}{ Uraian } & \multicolumn{6}{|c|}{ Tingkat kepentingan } & \multicolumn{6}{|c|}{ Tingkat kinerja } \\
\hline & \multicolumn{5}{|c|}{ Tingkat penilaian } & \multirow{3}{*}{ Total } & \multicolumn{5}{|c|}{ Tingkat penilaian } & \multirow{3}{*}{ Total } \\
\hline & STP & $\mathrm{TP}$ & $\mathrm{CP}$ & $\mathrm{P}$ & $\mathrm{SP}$ & & STB & $\mathrm{TB}$ & $\mathrm{CB}$ & B & SB & \\
\hline & 1 & 2 & 3 & 4 & 5 & & 1 & 2 & 3 & 4 & 5 & \\
\hline $\begin{array}{l}\text { Jumlah } \\
\text { responden }\end{array}$ & 0 & 0 & 9 & 16 & 25 & \multirow{2}{*}{$\begin{array}{r}50 \\
100\end{array}$} & 0 & 0 & 19 & 23 & 8 & \multirow{2}{*}{$\begin{array}{c}50 \\
100\end{array}$} \\
\hline Persentase $(\%)$ & 0 & 0 & 18 & 32 & 50 & & 0 & 0 & 38 & 46 & 16 & \\
\hline $\begin{array}{l}\text { Jumlah bobot } \\
\text { penilaian }\end{array}$ & 0 & 0 & 27 & 64 & 125 & 216 & 0 & 0 & 57 & 92 & 40 & 189 \\
\hline \multicolumn{6}{|c|}{ Skor rata - rata $(y)$} & 4.32 & \multicolumn{5}{|c|}{ Skor rata - rata $(\mathrm{x})$} & 3.78 \\
\hline
\end{tabular}

Sumber : Hasil Penelitian 2019

Dari aspek Kejelasan Informasi seperti ditunjukkan pada Tabel III, menganggap Kejelasan Informasi Sangat Penting dengan $50 \%$ responden, dengan jumlah bobot penilaian 125, dengan rata-rata tingkat penilaian 4,32. Sedangkan ditilik 
dari nilai kinerja pegawai sebagian besar pengunjung perpustakaan Unihaz menganggap baik (46\%) dengan bobot penilaian 92, dengan rata-rata tingkat penilaian 3,78.

Tabe IV

Nilai kepentingan dan kinerja dilihat dari Kecepatan Pelayanan

\begin{tabular}{|c|c|c|c|c|c|c|c|c|c|c|c|c|}
\hline \multirow{4}{*}{ Uraian } & \multicolumn{6}{|c|}{ Tingkat kepentingan } & \multicolumn{6}{|c|}{ Tingkat kinerja } \\
\hline & \multicolumn{5}{|c|}{ Tingkat penilaian } & \multirow{3}{*}{ Total } & \multicolumn{5}{|c|}{ Tingkat penilaian } & \multirow{3}{*}{$\begin{array}{c}\text { Tot } \\
\text { al }\end{array}$} \\
\hline & STP & TP & $\mathrm{CP}$ & $\mathrm{P}$ & SP & & STB & TB & CB & B & SB & \\
\hline & 1 & 2 & 3 & 4 & 5 & & 1 & 2 & 3 & 4 & 5 & \\
\hline $\begin{array}{l}\text { Jumlah } \\
\text { responden }\end{array}$ & 0 & 0 & 7 & 18 & 25 & \multirow{2}{*}{$\begin{array}{r}50 \\
100 \\
\end{array}$} & 0 & 0 & 17 & 26 & 7 & \multirow{2}{*}{$\begin{array}{c}50 \\
100\end{array}$} \\
\hline Persentase & 0 & 0 & 14 & 36 & 50 & & 0 & 0 & 34 & 52 & 14 & \\
\hline $\begin{array}{l}\text { Jumlah bobot } \\
\text { penilaian }\end{array}$ & 0 & 0 & 21 & 72 & 125 & 218 & 0 & 0 & 51 & 104 & 35 & 190 \\
\hline & $\mathrm{rr}$ & & & & & 4.36 & & Sko & $a-r$ & (x) & & $\begin{array}{l}3.8 \\
\end{array}$ \\
\hline
\end{tabular}

Sumber : Hasil Penelitian 2019

Dari aspek Kecepatan Pelayanan seperti diperlihatkan dalam Tabel IV, bahwa Kecepatan Pelayanan Sangat Penting dengan $50 \%$ responden, dengan jumlah bobot penilaian 125 , dengan rata-rata tingkat penilaian 4,36. Sedangkan ditinjau dari nilai kinerja pegawai sebagian besar pengunjung perpustakaan Unihaz menganggap baik (52 $\%$ ) dengan bobot penilaian 104, dengan rata-rata tingkat penilaian 3,8

\section{Tabel V}

\section{Nilai kepentingan dan kinerja dilihat dari Jaringan Internet}

\begin{tabular}{|c|c|c|c|c|c|c|c|c|c|c|c|c|}
\hline \multirow{4}{*}{ Uraian } & \multicolumn{6}{|c|}{ Tingkat kepentingan } & \multicolumn{6}{|c|}{ Tingkat kinerja } \\
\hline & \multicolumn{5}{|c|}{ Tingkat penilaian } & \multirow{3}{*}{ Total } & \multicolumn{5}{|c|}{ Tingkat penilaian } & \multirow{3}{*}{$\begin{array}{c}\text { Tot } \\
\text { al }\end{array}$} \\
\hline & STP & $\mathrm{TP}$ & $\mathrm{CP}$ & $\mathrm{P}$ & $\mathrm{SP}$ & & STB & $\mathrm{TB}$ & $\mathrm{CB}$ & B & SB & \\
\hline & 1 & 2 & 3 & 4 & 5 & & 1 & 2 & 3 & 4 & 5 & \\
\hline $\begin{array}{l}\text { Jumlah } \\
\text { responden }\end{array}$ & 0 & 0 & 5 & 11 & 34 & 50 & 0 & 0 & 9 & 25 & 16 & 50 \\
\hline Persentase $(\%)$ & 0 & 0 & 10 & 22 & 68 & 100 & 0 & 0 & 18 & 50 & 32 & 100 \\
\hline $\begin{array}{l}\text { Jumlah bobot } \\
\text { penilaian }\end{array}$ & 0 & 0 & 15 & 44 & 170 & 229 & 0 & 0 & 27 & 100 & 80 & 207 \\
\hline \multicolumn{6}{|c|}{ Skor rata - rata $(y)$} & 4.58 & \multicolumn{5}{|c|}{ Skor rata - rata $(\mathrm{x})$} & 4,14 \\
\hline
\end{tabular}

Sumber : Hasil Penelitian 2019

Dari aspek Jaringan Internet seperti diperlihatkan dalam Tabel V, bahwa Jaringan Internet Sangat Penting dengan $68 \%$ responden, dengan jumlah bobot penilaian 170, dan dengan rata-rata tingkat penilaian 4,58. Sedangkan ditinjau dari nilai kinerja pegawai sebagian besar pengunjung perpustakaan Unihaz menganggap baik (50 $\%$ ) dengan bobot penilaian 100, dan dengan rata-rata tingkat penilaian 4,14. 


\section{Tabel VI}

Nilai kepentingan dan kinerja dilihat dari Keramahan Pegawai

\begin{tabular}{|c|c|c|c|c|c|c|c|c|c|c|c|c|}
\hline \multirow{4}{*}{ Uraian } & \multicolumn{6}{|c|}{ Tingkat kepentingan } & \multicolumn{6}{|c|}{ Tingkat kinerja } \\
\hline & \multicolumn{5}{|c|}{ Tingkat penilaian } & \multirow{3}{*}{ Total } & \multicolumn{5}{|c|}{ Tingkat penilaian } & \multirow{3}{*}{$\begin{array}{l}\text { Tot } \\
\text { al }\end{array}$} \\
\hline & STP & TP & $\mathrm{CP}$ & $\mathrm{P}$ & SP & & STB & TB & $\mathrm{CB}$ & B & SB & \\
\hline & 1 & 2 & 3 & 4 & 5 & & 1 & 2 & 3 & 4 & 5 & \\
\hline $\begin{array}{l}\text { Jumlah } \\
\text { responden }\end{array}$ & 0 & 0 & 14 & 26 & 10 & 50 & 0 & 0 & 12 & 27 & 11 & 50 \\
\hline Persentase (\%) & 0 & 0 & 28 & 52 & 20 & 100 & 0 & 0 & 24 & 54 & 22 & 100 \\
\hline $\begin{array}{l}\text { Jumlah bobot } \\
\text { penilaian }\end{array}$ & 0 & 0 & 42 & 104 & 50 & 196 & 0 & 0 & 36 & 108 & 55 & 199 \\
\hline \multicolumn{6}{|c|}{ Skor rata - rata (y) } & 3,92 & \multicolumn{5}{|c|}{ Skor rata - rata $(\mathrm{x})$} & 3.98 \\
\hline
\end{tabular}

Sumber : Hasil Penelitian 2019

Dari aspek Keramahan Pegawai seperti diperlihatkan dalam Tabel VII, bahwa Keramahan Pegawai Penting dengan $52 \%$ responden, dengan jumlah bobot penilaian 104, dan dengan rata-rata tingkat penilaian 3,92. Sedangkan dilihat dari nilai kinerja pegawai sebagian besar pengunjung perpustakaan Unihaz menganggap baik (54\%) dengan bobot penilaian 108. Dan dengan rata-rata tingkat penilaian 3,98.

\section{Tabel VII}

Nilai kepentingan dan kinerja dilihat dari Kenyamanan Ruang Baca

\begin{tabular}{|c|c|c|c|c|c|c|c|c|c|c|c|c|}
\hline \multirow{4}{*}{ Uraian } & \multicolumn{6}{|c|}{ Tingkat kepentingan } & \multicolumn{6}{|c|}{ Tingkat kinerja } \\
\hline & \multicolumn{5}{|c|}{ Tingkat penilaian } & Total & \multicolumn{5}{|c|}{ Tingkat penilaian } & \multirow[t]{2}{*}{ Total } \\
\hline & $\begin{array}{l}\text { ST } \\
\text { P }\end{array}$ & TP & $\mathrm{CP}$ & $\mathrm{P}$ & SP & & STB & TB & $\mathrm{CB}$ & B & SB & \\
\hline & 1 & 2 & 3 & 4 & 5 & & 1 & 2 & 3 & 4 & 5 & \\
\hline Jumlah responden & 0 & 0 & 5 & 15 & 30 & 50 & 0 & 0 & 11 & 19 & 20 & 50 \\
\hline Persentase (\%) & 0 & 0 & 10 & 30 & 60 & 100 & 0 & 0 & 22 & 38 & 40 & 100 \\
\hline $\begin{array}{l}\text { Jumlah bobot } \\
\text { penilaian }\end{array}$ & 0 & 0 & 15 & 60 & 150 & 225 & o & 0 & 33 & 76 & 100 & 209 \\
\hline Sko & ata & ta & & & & 4.5 & & kor $\mathbf{r}$ & $a-r$ & (x) & & 4,18 \\
\hline
\end{tabular}

Dari aspek Kenyamanan Ruang Baca seperti diperlihatkan dalam Tabel VIII, bahwa Kenyamanan Ruang Baca Sangat Penting dengan $60 \%$ responden, dengan jumlah bobot penilaian 150 , dan dengan rata-rata tingkat penilaian 4,5 . Sedangkan dilihat dari nilai kinerja pegawai sebagian besar pengunjung perpustakaan Unihaz menganggap Sangat Baik 
(40\%) Responden, dengan bobot penilaian 100, dan dengan rata-rata tingkat penilaian 4,18 .

Selanjutnya atas dasar rata-rata Penilaian Tingkat Kepentingan dan Tingkat Kinerja seperti tersebut pada Tabel II sampai dengan Tabel VII diatas, dilakukan perhitungan Indeks kepuasan Pengunjung sebagai berikut:

Tabel VIII

Tingkat Kepuasan Pengunjung

\begin{tabular}{|c|c|c|c|c|}
\hline $\begin{array}{l}\text { Customer Satisfaction Index } \\
\text { (CSI) Tingkat Kepuasan } \\
\text { PengunjungAspek produk }\end{array}$ & $\begin{array}{l}\text { Rata-rata } \\
\text { tingkat } \\
\text { kepentingan }\end{array}$ & $\begin{array}{l}\text { Importance } \\
\text { weighting } \\
\text { factor }(\%)\end{array}$ & $\begin{array}{c}\text { Rata-rata } \\
\text { tingkat } \\
\text { kinerja }\end{array}$ & $\begin{array}{l}\text { Weighted } \\
\text { score } \\
(\%)\end{array}$ \\
\hline Ketersediaan Referensi & 4,68 & 17,75 & 3,92 & 0,69596 \\
\hline Kejelasan Informasi & 4,32 & 16,39 & 3,78 & 0,61948 \\
\hline Kecepatan Pelayanan & 4,36 & 16,54 & 3,80 & 0,62853 \\
\hline Jaringan Internet & 4,58 & 17,37 & 4,14 & 0,71932 \\
\hline Keramahan Pegawai & 3,92 & 14,87 & 3,98 & 0,59187 \\
\hline Kenyamanan Ruang Baca & 4,50 & 17,07 & 4,18 & 0,71358 \\
\hline Total & 26,36 & 100 & 23,80 & \\
\hline Weighted total & & & & 3,96874 \\
\hline $\begin{array}{c}\text { Satisfaction index (\%) } \\
(\mathrm{CSI}=(\mathrm{WT}: 6) \times 100 \%)\end{array}$ & \multicolumn{3}{|c|}{$(3,99804: 6) \times 100 \%$} & 66,1457 \\
\hline
\end{tabular}

Sumber: diolah dari Tabel II s/d VII

Besaran Angka Customer Satisfaction Indeks (CSI) atau Indeks Kepuasan Pengunjung sebesar 66,634 \%, tersebut pada Tabel X di atas, menunjukkan bahwa Pengunjung Perpustakaan Universitas Prof. Dr. Hazairin, SH Bengkulu dapat dikatakan puas terhadap pelayanan yang mereka terima, atau dengan kata lain kinerja perpustakaan mampu memberikan kepuasan kepada Pengunjung Perpustakaan.

\section{KESIMPULAN}

1. Penilaian tertinggi untuk tingkat kepentingan bagi Pengunjung adalah aspek Ketersediaan Referensi, diikuti aspek aspek Jaringan Internet, Kenyamanan Ruang Baca, Kecepatan Pelayanan, Kejelasan Informasi, serta aspek Keramahan Pegawai 
2. Penilaian tertinggi untuk tingkat Kinerja pegawai adalah aspek Kenyamanan Ruang Baca, selanjutnya diikuti aspek aspek Jaringan Internet, Keramahan Pegawai, Ketersediaan Referensi, Kecepatan Pelayanan serta Kejelasan Informasi

3. Nilai Customer Satisfaction Indeks (CSI) sebesar 66,1457 \%, menunjukkan Tingkat Kepuasan Pengunjung Perpustakaan Universitas Prof. Dr. Hazairin, SH Bengkulu dapat dikatakan puas.

\section{SARAN}

1. Memperhatikan tingkat kepentingan Responden yang tercermin dari aspek aspek yang mereka anggap sangat penting, maka asfek asfek yang perlu diperioritaskan untuk ditingkatkan agar kebutuhan Pengunjung Perpustakaan Unihaz terpenuhi dan kepuasannya meningkat adalah asfek-asfek Ketersediaan Referensi, Jaringan Internet, serta kenyamanan ruang baca. Sedangkan asfek asfek yang perlu mendapat perhatian agar kepentingan pengunjung Perpustakaan dapat terpenuhi dan mendapat kepuasan adalah Kecepatan Pelayanan, Kejelasan Informasi, serta Keramahan Pegawai.

2. Kinerja Pegawai Perpustakaan Unihaz yang perlu diperbaiki dan ditingkatkan agar kepuasan Pengunjung Perpustakaan Unihaz meningkat, meliputi kejelasan Informasi, Kecepatan Pelayanan serta Keramahan Pegawai Perpustakaan Unihaz.

\section{DAFTAR PUSTAKA}

Sinungan, 2003. Manajemen Sumber daya Manusia. Bandung CV.Pustaka Setia;

Siagian, Sondang P, 2002, Manajemen Surnber Daya Manusia. Bumi Aksara, Jakarta Cetakan Kelima;

Supranto,j.2001pengukuran tingkat kepusaan pelanggan untuk meningkatkan pangsan pasar PT.RenitaCipta Jakarta (http://pse.litbang.deptan.go.id/ind/pdffiles/JAE\%2024-1c.pdf);

http://amarsuteja.blogspot.com/2013/01/kepuasan-pengunjung-perpustakaan.html

(https://www.kajianpustaka.com/2012/11/ perpustakaan.html)

https://www.seputarpengetahuan.co.id/ 2016/10/ pengertian-pelayanan-menurut-para-ahlilengkap.html 